\title{
PROTEÇÃO SOCIAL VERSUS ADOECIMENTO POR CARCINOMA EPIDERMÓIDE: CONTRIBUIÇÕES DO SERVIÇO SOCIAL
}

\author{
Social Protection versus disease from Epidermoid Carcinoma: contributions of \\ Social Work \\ Priscila Ribeiro Lima ${ }^{1}$ \\ Fernanda dos Reis Melo ${ }^{2}$ \\ Letícia Batista Silva ${ }^{3}$
}

\begin{abstract}
Resumo
Este artigo apresenta uma breve discussão sobre o papel fundamental da proteção social, com destaque para as que se apresentam no âmbito do trabalho, no contexto de adoecimento por carcinoma epidermóide. É um tipo de câncer com grande expressividade dentro do campo da oncologia que acomete, em especial, homens em idade laborativa, o que justifica sua escolha como objeto de problematização deste texto. Essa discussão torna-se importante no sentido de apontar elementos que contribuam para a reflexão crítica no debate sobre a garantia e ampliação dos direitos sociais frente ao cenário atual de contrarreforma do Estado brasileiro.
\end{abstract}

Palavras-chave: Proteção Social. Trabalho. Serviço Social. Oncologia.

\begin{abstract}
This article presents a brief discussion about the fundamental role of social protection, highlighting those that present themselves in the labor extent, in the context of the disease process by epidermoid carcinoma. A type of cancer with great expressiveness in the field of oncology, usually affecting men in productive age, which justifies it as choice as object of problematization of this text. This discussion becomes important in the sense of pointing out elements that could contribute to the critical reflection on the debate about the social rights' warranty and expansion against the current scenery of counter-reformation in the Brazilian Estate.
\end{abstract}

Keywords: Social Protection. Work. Social Work. Oncology.

\section{INTRODUÇÃO}

Este texto é fruto de inserção no Programa de Residência Multiprofissional em Oncologia do Instituto Nacional de Câncer José de Alencar Gomes da Silva (INCA), a

\footnotetext{
1 Assistente social, Mestranda em Serviço Social do PPGSS/UERJ. Telefone 21 24090962, e-mail: pris.lima@bol.com.br.

${ }^{2}$ Assistente Social do INCA, Mestre em Saúde Pública pela ENSP/FIOCRUZ, Doutoranda em Serviço Social do PPGSS/UERJ. E-mail: femelo@ig.com.br.

${ }^{3}$ Assistente Social do INCA, Mestre em Serviço Social pela UFRJ, Doutoranda em Serviço Social do PPGSS/UERJ. E-mail: leticiabatistas@gmail.com.

Serv. Soc. \& Saúde, Campinas, SP v. 13, n. 1 (17) p. 61-76 jan./jun. 2014 ISSN 1676-6806
} 
partir da lotação no Hospital do Câncer II (HC II) ${ }^{4}$, na Seção de Tecido Ósseo e Conectivo (TOC) $)^{5}$ no ano de 2012.

A experiência na referida clínica proporcionou o acompanhamento de usuários acometidos por carcinoma epidermóide ${ }^{6}$, no qual foi observado que a ausência de proteção social ou a oferta limitada desta, em especial, no âmbito do trabalho, possuem impactos no processo de tratamento. Há impactos sociais no sentido da garantia de todas as necessidades exigidas para o tratamento desta patologia.

O tratamento é espoliante e gera inúmeras necessidades sociais que, por sua vez, estão condicionadas e determinadas pelas condições de vida e de trabalho do usuário. Assim, a partir de uma realidade concreta, este artigo busca oferecer elementos para contribuir com a reflexão crítica acerca da centralidade da proteção social, com ênfase na esfera trabalhista, frente às necessidades sociais oriundas das exigências do processo de tratamento oncológico.

\section{Breves considerações sobre a Proteção Social no âmbito do trabalho em tempos de neoliberalismo}

Nos anos 1990, concomitante com a implementação da noção de Seguridade Social $^{7}$, o Brasil adota a política neoliberal que, por sua vez, constitui-se em recomendações dos organismos financeiros internacionais de transformações no Estado com intuito de atender os interesses de acumulação do capital, leia-se, restrição do

\footnotetext{
${ }^{4} \mathrm{O}$ HC II é uma das cinco unidades assistenciais do INCA que, além dos serviços de ensino e pesquisa, presta assistência especializada nas áreas de TOC, com oferta de tratamento nas modalidades de cirurgia, quimioterapia e radioterapia.

${ }^{5}$ TOC é uma clínica que trata os tumores de partes moles, incluindo o câncer de pele, com exceção dos que se localizam na região da cabeça e do pescoço. Atualmente é o único serviço que oferece tratamento para esses tipos de tumores no Estado do Rio de Janeiro.

${ }^{6}$ É um tipo de tumor maligno que, em geral, surge na pele. Apresenta-se na forma de manchas avermelhadas e irregulares e é mais comum nas áreas mais expostas do corpo. Possui evolução rápida e risco de espalhar-se para outras áreas do corpo. Fontes:

http://drauziovarella.com.br/cancer/carcinoma- epidermoide-de-pele/ e http://www2.inca.gov.br/wps/wcm/connect/tiposdecancer/site/home/pele_nao_melanoma/diagnostico. Acesso em: nov. 2012.

${ }^{7}$ A partir da Carta Magna de 1988, institui-se a noção de seguridade social com inscrição das políticas de previdência social, saúde e assistência social no patamar das políticas públicas. A saúde passa a ser uma política pública universal. A assistência social ganha estatuto de política pública, assegurando proteção à família, maternidade, infância, adolescência e velhice, sem necessidade de contribuição e com acesso para quem dela necessitar. Sobre a previdência social, na existência de vínculo trabalhista, passa a ser obrigatória a inscrição via Carteira de Trabalho e Previdência Social (CTPS) assinada. Assim como

alguns trabalhadores rurais, visto que reconhece o direito à aposentadoria não integralmente contributiva a estes e, também, oferece estatuto de direito do trabalhador ao seguro-desemprego. Outro aspecto destacado é a possibilidade de inscrição do trabalhador de forma individual.

Serv. Soc. \& Saúde, Campinas, SP v. 13, n. 1 (17) p. 61-76 jan./jun. 2014 ISSN 1676-6806
} 
Estado no atendimento das necessidades sociais e maximização para o capital (BEHRING, 2003).

Esse processo de redução do papel social do Estado é caracterizado por Behring (2003) como contrarreforma do Estado e é marcado pelo período de uma política orientada para a privatização, focalização, fragmentação e (des)financiamento das políticas sociais. No campo do trabalho, a política neoliberal materializa-se com a implementação da reestruturação produtiva, que por sua vez, opera alterações na esfera da produção, consumo e relações de trabalho. Dessa forma, inicia-se um amplo processo de desmonte dos direitos trabalhistas.

Essa nova configuração do Estado frente ao mundo do trabalho proporciona a intensificação da precarização das relações de trabalho, com a flexibilização dos contratos de trabalho, terceirização e crescimento do trabalho informal (HARVEY, 1993; ANTUNES, 2002).

Os autores Salvador e Amorim destacam que:

[...] o assalariamento sem carteira assinada e o trabalho autônomo constituem parte expressiva do conjunto dos ocupados, cuja precariedade de inserção decorre da falta de acesso ao contrato de trabalho padrão, da descontinuidade da relação de trabalho e da instabilidade dos rendimentos [...] esses trabalhadores estão no núcleo mais frágil do mercado de trabalho e são candidatos potenciais às políticas de Assistência Social do Estado (SALVADOR; AMORIM, 2010, p. 37).

Se por um lado, os trabalhadores formais que possuem acesso à Previdência Social não são o núcleo mais frágil do mercado de trabalho, por outro, também sofrem os constrangimentos impostos pelo processo de contrarreforma do Estado. Boschetti (2009) aponta algumas das transformações realizadas na legislação da Previdência Social com vistas à redução nos valores reais dos benefícios e abertura para o fomento e consolidação da previdência privada complementar.

Nas palavras da autora:

Diversas contrarreformas, como a da Previdência de 1998, 2002 e 2003, sendo as primeiras no Governo Fernando Henrique Cardoso e outra no Governo Lula, restringiram direitos, reforçaram a lógica do seguro, reduziram valor de benefícios, abriram caminho para a privatização e para expansão dos planos privados, para os fundos de pensão, ampliaram o tempo de trabalho e contribuição para obter a aposentadoria (BOSCHETTI, 2009, p. 333). 
Moreira (2010) sinaliza que até 1998 foram realizadas 99 modificações nos planos de benefícios da Previdência Social, das quais 39 delas referem-se à supressão de direitos e 48 representam mudanças nos direitos e obrigações.

Uma das principais mudanças identificadas no sistema previdenciário nesse processo de contrarreforma do Estado foi a instituição do fator previdenciário com base em princípios atuariais que, na prática, traduz-se em redução no valor dos benefícios. Por sua vez, tal redução pode significar dificuldade dos trabalhadores em se ausentarem do trabalho, por motivo de afastamento temporário para fins de tratamento de saúde ou permanente, como nos casos de aposentadoria, por exemplo.

Para os trabalhadores informais, sem acesso à Previdência Social, ausentarem-se do trabalho pode representar cerceamento à proteção social, uma vez que apesar da política de Assistência Social apontar acesso, no plano legal, a quem dela necessitar, com o processo de desmonte dos direitos sociais esta política encontra-se restrita ao atendimento das camadas mais empobrecidas da população por meio de benefícios, programas e serviços com rigorosos critérios de elegibilidade e provisão apenas dos mínimos sociais.

Nesse sentido, Mota (2007) identifica a existência de uma relação tensional entre previdência e assistência, na qual as coberturas da previdência destinam-se aos trabalhadores com vínculo formal e as da assistência aos não inseridos no mercado formal de trabalho. Entretanto, apesar de parecer coerente e garantir proteção social a todos, isto é, oferta dos benefícios da previdência para os trabalhadores formais e da assistência para os não inseridos no mercado formal, nos países de capitalismo periférico, nos quais o pleno emprego não se generalizou, como é o caso do Brasil, esta combinação deixa completamente descobertos os pobres economicamente ativos ${ }^{8}$.

Cabe salientar, por fim, as considerações de Antunes (2002) que sinalizam uma conjuntura extremamente desfavorável em relação à garantia, quiçá à defesa de novos direitos trabalhistas no contexto do neoliberalismo, pois a reestruturação produtiva afeta não só aspectos materiais, mas aspectos subjetivos da classe trabalhadora, como a consciência de classe.

Nesse contexto, o trabalhador equivale a uma mercadoria que requer boa saúde para a execução das atividades laborais e, quando possui sua saúde totalmente

\footnotetext{
8 A autora define os pobres economicamente ativos como "os que têm trabalho, mas com renda insuficiente para garantir suas condições de vida” (MOTA, 2007).

Serv. Soc. \& Saúde, Campinas, SP v. 13, n. 1 (17) p. 61-76 jan./jun. 2014 ISSN 1676-6806
} 
consumida, às vezes pelo próprio processo de trabalho, torna-se inapto e é substituído como qualquer outro componente da produção.

\section{O caráter multifacetado do adoecimento oncológico: a questão do carcinoma epidermóide}

O câncer ${ }^{9}$ representa a segunda causa de mortes no Brasil e, portanto, é considerado um problema de saúde pública, com expectativa de aumento da sua incidência tanto no Brasil como em proporções mundiais (BRASIL, 2011a).

De acordo com a estimativa INCA 2012, o câncer de pele não melanoma ${ }^{10}$ tratados na seção de TOC do HC II - será o mais incidente em 2012 e 2013 e o segundo mais frequente na região Sudeste. Foram apontados 134.170 novos casos no Brasil em 2012, o que representa aproximadamente $26 \%$ dos tumores malignos registrados no país. Na região Sudeste a estimativa foi de 86.490 novos casos enquanto no Rio de Janeiro este número é de 27.400 (BRASIL, 2011a).

O câncer de pele não melanoma abrange tumores de diferentes linhagens, sendo o carcinoma epidermóide o segundo mais incidente, com $25 \%$ do total de casos. Desta forma, este tipo de neoplasia ganha lugar de destaque entre os tumores de pele não melanoma mais prevalentes, conforme destaca Favalli et al.:

O carcinoma epidermóide de pele é a segunda neoplasia maligna de pele mais comum no mundo, perdendo apenas para o carcinoma basocelular. A sua incidência aumenta após os 40 anos de idade e este tumor é mais comum em homens (15,5 casos/100.000 pessoas). O risco de desenvolver um carcinoma epidermóide durante toda a vida é de 4 a 14\% (FAVALLI et al., 2007, p. 301).

Em geral, os tumores de pele não melanoma possuem crescimento lento, localmente invasivos e com baixo risco de metástase ${ }^{11}$ à distância. Entretanto, o carcinoma epidermóide apresenta evolução rápida. É uma neoplasia de bom

\footnotetext{
${ }^{9}$ Câncer é um termo genérico utilizado para classificar um conjunto de mais de 100 doenças que possuem causas variadas, com fatores que variam entre internos e externos ao organismo e cuja principal característica que as identifica é o crescimento desordenado das células, que por sua vez, tendem a invadir tecidos e órgãos vizinhos (BRASIL, 2005).

${ }^{10}$ Segundo a Estimativa 2012 há uma subnotificação dos registros de câncer de pele não melanoma em âmbito mundial. No Brasil isto se dá devido ao subdiagnóstico. Portanto, deve ser considerada como uma estimativa mínima (BRASIL, 2011a).

${ }^{11}$ Metástase é um termo utilizado na oncologia para designar outros focos do tumor longe do local de sua origem, ou seja, quando as células cancerosas de um tumor se espalham para outras partes do corpo. Fonte: www.inca.gov.br:

http://www1.inca.gov.br/situacao/arquivos/carcinogenese.pdf. Acesso em: 20 nov. 2012.

Serv. Soc. \& Saúde, Campinas, SP v. 13, n. 1 (17) p. 61-76 jan./jun. 2014 ISSN 1676-6806
} 
prognóstico $^{12}$ desde que tratada nos estágios iniciais e com a terapêutica adequada. Já os casos em que o diagnóstico acontece tardiamente, este tipo de câncer pode levar a sequelas e deformidades graves (BRASIL, 2011a).

Especificamente sobre o carcinoma epidermóide, os estudos apontam que o desenvolvimento desta patologia está associado à exposição excessiva ao sol, cicatrizes de queimaduras ou úlceras, imunidade comprometida, dentre outros. Sua incidência é maior em pessoas acima dos 40 anos de idade e do sexo masculino. Ou seja, acomete, principalmente, homens em idade laborativa o que, por sua vez, justifica a escolha desta patologia como objeto de discussão do artigo (FAVALLI et al., 2007; BRASIL, 2011a).

Segundo Favalli et al. (2007), a importância do diagnóstico e do tratamento do carcinoma epidermóide é subestimada tanto pelos profissionais de saúde quanto pelas pessoas acometidas por esta patologia. E, tal fato, somado à dificuldade de acesso aos serviços de saúde corroboram o diagnóstico tardio, isto é, quando a doença já está em fase avançada e demanda tratamento complexo que, por sua vez, pode gerar sequelas graves e também cirurgias mutiladoras.

Com relação aos tratamentos propostos para controle ou cura do câncer, Batista Silva (2010) assinala que, em geral, são de longa duração e causam algum tipo de sequela, seja pelos efeitos da radioterapia ${ }^{13}$, quimioterapia ${ }^{14}$ ou cirurgia $^{15}$, provocando repercussões físicas, sociais e subjetivas.

Sobre a situação do adoecimento oncológico, Batista Silva ressalta:

\footnotetext{
${ }^{12}$ A literatura especializada aponta que o carcinoma epidermóide tem grandes chances de cura, dadas as possibilidades terapêuticas disponíveis atualmente, desde que o diagnóstico seja precoce e o tratamento ocorra sem prejuízo do protocolo estabelecido para esta patologia (FAVALLI et al., 2007).

${ }^{13}$ É um método de tratamento local ou regional baseado no emprego de radiações ionizantes capazes de destruir células tumorais e/ou impedirem o seu aumento. É curativa quando busca a cura total do tumor; remissiva quando busca redução do tumor; profilática quando não há tumor, mas células neoplásicas dispersas; paliativa quando pretende a remissão de alguns sintomas; e ablativa quando o objetivo é

suprimir a função de um órgão do corpo. Os principais efeitos colaterais são: cansaço, perda de apetite e dificuldade para ingerir alimentos e reação da pele. Fonte: www.inca.gov.br:

http://www2.inca.gov.br/wps/wcm/connect/cancer/site/tratamento. Acesso em: 03 nov. 2012.

${ }^{14}$ É um método de tratamento baseado na administração de um ou mais medicamentos constituídos de compostos químicos, chamados quimioterápicos, com a finalidade de atingir populações de células doentes que formam o tumor. É classificada de acordo com o objetivo, isto é: é considerada curativa quando pode ser utilizada para controle completo do tumor; neoadjuvante quando é realizada antes da cirurgia para se obter a redução parcial do tumor; adjuvante quando é realizada após da cirurgia, com

objetivo de esterilizar células residuais ou circulantes; e paliativa quando propõe melhorar a qualidade da sobrevida do paciente. Os principais efeitos colaterais são: fraqueza, diarreia, perda ou aumento de peso, feridas na boca, queda de cabelo e outros pelos do corpo, enjoo, vômitos e tonteiras. Fonte: www.inca.gov.br: http://www2.inca.gov.br/wps/wcm/connect/cancer/site/tratamento. Acesso em: 03 nov 2012.

${ }^{15}$ É um método de tratamento baseado na intervenção manual ou instrumental pelo médico cirurgião, co $\mathrm{m}$ vistas à retirada parcial ou total do tumor.

Serv. Soc. \& Saúde, Campinas, SP v. 13, n. 1 (17) p.61-76 jan./jun. 2014 ISSN 1676-6806
} 
A partir da doença diagnosticada, em princípio, inicia-se um processo de tratamento que solicita disponibilidade do sujeito enfermo para realização de uma série de exames, acompanhamentos e a própria proposta terapêutica (radioterapia, quimioterapia, cirurgia ou mesmo a combinação dessas propostas). A efetivação desse tratamento depende de condições concretas da oferta desses serviços pelo SUS e de condições de vida adequadas para que esse sujeito enfermo possa realizar o tratamento. Os determinantes da questão social influenciam fortemente as condições de efetivação desse tratamento [...] outro componente trata-se das famílias que precisam reorganizar-se para atender as necessidades de acompanhamento desse enfermo e da possível ausência de contribuição financeira (BATISTA SILVA, 2010, p. 183).

Ou seja, o tratamento oncológico, independente da modalidade terapêutica proposta, exige uma reorganização do sujeito para sua realização, inclusive pelo fato de que a cura ou sobrevida desse sujeito será influenciada, tanto pelas características próprias de malignidade, tipo e localização do tumor, como pela possibilidade do diagnóstico precoce e pela realização oportuna do tratamento que, por sua vez, será influenciada pela inserção social e econômica do usuário, pelo fato de que são necessárias condições tais como: acessibilidade aos serviços de saúde, disponibilidade para idas frequentes à unidade de saúde, dentre outras.

Neste sentido, vale ressaltar que as condições sociais, econômicas, ambientais, culturais e políticas são determinantes no processo saúde-doença, conforme indicado na Lei ${ }^{\circ} 8.080 / 1990$, quando afirma como fatores condicionantes e determinantes da saúde “entre outros, a alimentação, a moradia, o saneamento básico, o meio ambiente, o trabalho, a renda, a educação, o transporte, o lazer e o acesso aos bens e serviços essenciais" (BRASIL, 1990, artigo $3^{\circ}$ ). A partir dessa perspectiva, foi salientado o caráter histórico e social da saúde e sua expressão enquanto resultado da organização social e econômica de uma população.

Nesta direção, Batista Silva acrescenta:

No texto constitucional a saúde é garantida mediante políticas sociais e econômicas que visem à redução do risco de doença e de outros agravos e ao acesso universal e igualitário às ações e serviços para sua promoção, proteção e recuperação. A partir dessas concepções, a produção de saúde passa, necessariamente, por determinantes econômicos e sociais (BATISTA SILVA, 2010, p. 174).

No caso do adoecimento por carcinoma epidermóide o tratamento geralmente combina cirurgia e radioterapia. Duas modalidades de tratamento que, separadas ou em combinação, são bastante invasivas, com características espoliantes que impõem aos usuários algumas requisições. 
$\mathrm{Na}$ fase pré-operatória, o usuário é submetido a uma série de consultas e exames e até internações, o que exige frequência à unidade hospitalar. Isso significa necessidade de ausência do usuário no trabalho, assim como de outro ente familiar, uma vez que

fragilizado pelo processo de tratamento é comum a necessidade de um acompanhante para realização dos procedimentos.

$\mathrm{O}$ afastamento do trabalho pode representar implicações sociais que impactam no processo de tratamento e na vida dos usuários, uma vez que acessar o auxílio-doença significa perda na composição da renda familiar, pois o valor do benefício é de $91 \%$ da média dos salários de contribuição e, além disso, as gratificações e salários indiretos não são pagos aos trabalhadores em afastamento.

Se para os trabalhadores com acesso à Previdência Social o afastamento do trabalho traduz-se em alterações na vida do sujeito adoecido e em dificuldades no cumprimento das exigências oriundas do processo de tratamento, no caso dos trabalhadores sem acesso à Previdência Social estas dificuldades são potenci alizadas.

Um conjunto significativo de direitos, no campo da oncologia, destina-se ao usuários que possuem acesso à Previdência Social, como o auxílio-doença ou licença médica, aposentadoria por invalidez, isenção de Imposto de Renda (IR) na aposentadoria, o saque do Programa de Integração Social (PIS), do Programa de Formação do Patrimônio do Servidor Público (PASEP) e do Fundo de Garantia por Tempo de Serviço (FGTS).

No caso dos trabalhadores sem acesso à Previdência Social existe, no plano legal, direitos inscritos na Política de Assistência Social que poderiam oferecer-lhes proteção social, como o passe para uso em transporte coletivo para doentes crônicos

(Rio Card Especial ${ }^{16}$ e Vale Social), o Tratamento Fora de Domicílio (TFD) ${ }^{17}$, a Isenção de Imposto de Renda sobre a Propriedade Predial e Territorial Urbana (IPTU) ${ }^{18}$, a isenção de Imposto sobre Produtos Industrializados (IPI), o Imposto sobre Circulação d e Mercadorias e Serviços (ICMS $)^{19}$ e Imposto sobre a Propriedade de Veículos

\footnotetext{
16 A partir de agosto de 2012 a gratuidade nos ônibus para doentes crônicos, no Rio de Janeiro foi condicionada a critério de hipossuficiência, ou seja, a concessão do passe passa por critério socioeconômico, a saber, renda familiar inferior a três salários mínimos.

O TFD destina-se às pessoas que necessitam deslocar-se até outro município para realização de tratamento de saúde que os seus municípios não oferecem. Não contempla a necessidade dos deslocamentos menores que $50 \mathrm{~km}$ de distância e em regiões metropolitanas. Fonte: Portaria $\mathrm{SAS} \mathrm{n}^{\circ}$ 55, de 24 de fevereiro de 1999.

${ }^{18}$ A isenção do IPTU para portadores de doença crônica é prevista em alguns municípios, conforme sua lei orgânica (BRASIL, 2011b).

Conforme legislação específica do município (BRASIL, 2011b).

Serv. Soc. \& Saúde, Campinas, SP v. 13, n. 1 (17) p. 61-76 jan./jun. 2014 ISSN 1676-6806
} 
Automotores (IPVA) ${ }^{20}$ na aquisição de veículos adaptados e o Benefício de Prestação Continuada $(\mathrm{BPC})^{21}$.

Entretanto, diante do contexto de contrarreforma do Estado os direitos apresentados estão destinados às parcelas mais empobrecidas da população, com critérios de elegibilidade que nem sempre permitem acessos aos usuários matriculados nas unidades de saúde. Há casos em que os usuários ficam sem qualquer tipo de proteção social, recorrendo às ações filantrópicas oferecidas dentro das instituições em que são atendidos ou mesmo fora delas.

A filantropia, assim como a transferência da responsabilidade do Estado para a sociedade civil é também parte da política neoliberal em curso no Brasil como estratégias de enfrentamento às múltiplas expressões da questão social, conforme sinaliza Iamamoto:

[...] tornam-se objeto de ações filantrópicas e de benemerência e de programas focalizados de combate à pobreza, que acompanham a mais ampla privatização da política social pública, cuja implementação passa a ser delegada a organismos privados da sociedade civil, o terceiro setor (IAMAMOTO, 2009, p. 22).

Então, questões como acessibilidade, disponibilidade de rede de apoio e manutenção das suas necessidades básicas e de sua família tornam-se elementos fundamentais no que se refere à possibilidade de adesão e continuidade do tratamento.

Nas situações de doença avançada, em que o tratamento pode expor o sujeito a sequelas que impõem perda de autonomia e vão de encontro às suas capacidades laborativas, a impossibilidade de retorno ao trabalho apresenta-se como mais um fator de mudança na vida do usuário e de sua família, visto que o fato do afastamento significa perda ou ausência de renda do sujeito adoecido que, em muitos casos, é o provedor da família.

Neste sentido, podemos inferir que no contexto de adoecimento por carcinoma epidermóide, cujo tratamento muitas vezes é longo e demanda afastamento das atividades laborais, toda a família pode ser impactada, pois apesar do crescimento do

\footnotetext{
${ }^{20}$ Conforme legislação específica do município (BRASIL, 2011b).

${ }^{21} \mathrm{O}$ BPC é um benefício assistencial no valor de um salário mínimo destinado aos idosos a partir dos 65 anos e às pessoas em qualquer idade; neste último caso, para aquelas incapacitadas para o trabalho e para as atividades da vida diária por período igual ou superior a dois anos, desde que possuam renda familiar inferior a $1 / 4$ do salário mínimo. Fonte: Lei Orgânica da Assistência Social (LOAS), Lei n ${ }^{0}$ 8.742, de 7/12/1993; Leis $n^{\circ} 12.435$, de 06/07/2011 e n 12.470 , de 31/08/2011, que alteram dispositivos da LOAS e Decretos $\mathrm{n}^{\circ} 6.214$, de 26 de setembro de 2007 e $\mathrm{n}^{\circ} 6.564$, de 12 de setembro de 2008.

Serv. Soc. \& Saúde, Campinas, SP v. 13, n. 1 (17) p. 61-76 jan./jun. 2014 ISSN 1676-6806
} 
papel da mulher na provisão da família ${ }^{22}$ o homem ainda possui um papel central, principalmente no que se refere à questão socioeconômica, ainda com os maiores salários do mercado de trabalho, mesmo ocupando as mesmas funções.

\section{Proteção Social versus adoecimento por carcinoma epidermóide: os desafios postos para o trabalho do assistente social}

O adoecimento por carcinoma epidermóide torna-se um objeto relevante a ser estudado em virtude de sua magnitude dentro do campo da oncologia, por ser uma patologia curável e, ainda, pelo potencial de implicações sérias nos aspectos físicos e sociais dos sujeitos envolvidos, assim como pelo fato de que a questão da oncologia se inscreve nas questões do Sistema Único de Saúde (SUS).

Sabemos que as implicações do processo de tratamento atingem não só o sujeito adoecido como também sua família e/ou rede de apoio, já que o tratamento oncológico demanda disponibilidade de tempo, muitas vezes, com necessidade de um acompanhante para realização da terapêutica proposta. Esta pode exigir frequência diária ao hospital que, por conseguinte, acarreta em afastamento do trabalho - seja na inserção formal ou informal - com comprometimento da renda familiar ou ausência desta, dentre outras. Neste sentido, a proteção social é um fator determinante, tanto no que se refere ao processo de adoecimento quanto na garantia do tratamento oportuno na esfera da oncologia.

Contudo, observamos, cotidianamente, o processo de desmonte da política de proteção social, principalmente do trabalho, com fomento da privatização, terceirização, informalização e flexibilização das relações de trabalho, com alcance ao conjunto de toda a classe trabalhadora, inclusive aquela a mercê da assistência, que da mesma forma, participa do ciclo de reprodução do capital.

As crises do capital nunca são exclusivamente econômicas, são também sociais e políticas. Sendo assim, representam períodos de reorganização no âmbito econômico, político e social, expressão de iniciativas e interesses de classes (MOTA, 1996).

No contexto atual, de neoliberalismo, uma das estratégias de enfrentamento da crise é a implementação de mudanças no sistema de proteção social, orientadas pelos organismos financeiros internacionais, que preveem, dentre outros, redução dos gastos

\footnotetext{
${ }^{22}$ Os últimos estudos do Instituto Brasileiro de Geografia e Estatística (IBGE) apontam para um aumento da inserção das mulheres no mercado do trabalho, porém com menores remunerações comparadas aos homens.

Serv. Soc. \& Saúde, Campinas, SP v. 13, n. 1 (17) p.61-76 jan./jun. 2014 ISSN 1676-6806
} 
públicos, ampliação do setor privado lucrativo e o não lucrativo, e redução das contribuições sociais das empresas.

Como resultado desta política observa-se o desenvolvimento de políticas localizadas na pobreza, a transferência dos serviços para o setor privado e o desenvolvimento de atividades voluntárias complementares aos serviços públicos, conforme ressalta Iamamoto:

A atual desregulamentação das políticas públicas e dos direitos sociais desloca a atenção à pobreza para a iniciativa privada ou individual, impulsionada por motivações solidárias e benemerentes, submetidas ao arbítrio do indivíduo isolado e ao mercado e não à responsabilidade pública do Estado, com claros chamamentos à sociedade civil (IAMAMOTO, 2009, p. 22).

Neste cenário, a questão social deixa de ser objeto específico de atuação do Estado e passa a ser foco do empresariado e do "terceiro setor", como parte da formação de uma nova cultura.

Sobre esse aspecto Iamamoto infere:

As conquistas sociais acumuladas têm sido transformadas em causa de 'gastos sociais excedentes' que se encontrariam na raiz da crise fiscal dos Estados. A contrapartida tem sido a difusão da ideia liberal de que o 'bem-estar social' pertence ao foro privado dos indivíduos, famílias e comunidades. A intervenção do Estado no atendimento às necessidades sociais é pouco recomendada, transferida ao mercado e à filantropia, como alternativas aos direitos sociais que só existem na comunidade política [...] o pensamento neoliberal estimula um vasto empreendimento de 'refilantropização do social', e opera uma profunda despolitização da 'questão social' ao desqualificá-la como questão pública, questão política e questão nacional (IAMAMOTO, 2009, p. 22-23).

O Serviço Social enquanto categoria profissional inscrita na divisão social e técnica do trabalho atua na tensão entre produção da desigualdade, a rebeldia e o conformismo. Ou seja, as condições para o desenvolvimento da profissão estão relacionadas com o desenvolvimento da sociedade capitalista, da emergência da questão social - que não é senão a expressão das desigualdades de classe, que evidencia os trabalhadores enquanto classe - e, como tal, a necessidade de respostas políticas e não apenas no âmbito da caridade e da repressão.

Os assistentes sociais atuam em prol de garantir o acesso aos direitos e de socializar os meios de exercê-los. Desta forma, ao estimular a organização dos trabalhadores na defesa e na ampliação dos seus direitos, contribuem para dar visibilidade às necessidades e interesses dos sujeitos sociais na cena pública. 
Entretanto, ao inscrever-se na garantia de condições de vida dos trabalhadores, o Serviço Social encontra-se integrado à reprodução capitalista, uma vez que contribui para a reprodução da classe trabalhadora, indispensável para a geração de valor no sistema capitalista, através da mais-valia ${ }^{23}$.

Vale ressaltar que o assistente social é também classe trabalhadora e, como tal, submetido aos processos de precarização das condições de trabalho. Desta forma, a radicalização da questão social atravessa o cotidiano dos assistentes sociais e impõe novos desafios no que se refere à consolidação dos princípios éticos.

Segundo Iamamoto:

De um lado, ampliam-se as necessidades não atendidas pela maioria da população, pressionando as instituições públicas por uma demanda crescente de serviços sociais. De outro lado, esse quadro choca-se com a restrição dos recursos para as políticas sociais governamentais, coerente com os postulados neoliberais para área social, que provocam o desmonte das políticas públicas de caráter universal, ampliando a seletividade típica dos 'programas de combate à pobreza' e a mercantilização dos serviços sociais, favorecendo a capitalização do setor privado [...]. E o assistente social, que é chamado a implementar e viabilizar direitos sociais e os meios de exercê-los, vê-se tolhido em suas ações que dependem de recursos, condições e meios de trabalho cada vez mais escassos para operar as políticas sociais (IAMAMOTO, 2007, p. 148-149).

Coadunando com a autora, o documento do CFESS acrescenta:

A nova configuração da política de saúde vai impactar o trabalho do assistente social em diversas dimensões: nas condições de trabalho, na formação profissional, nas influências teóricas, na ampliação da demanda e na relação com os demais profissionais e movimentos sociais. Amplia-se o trabalho precarizado e os profissionais são chamados a amenizar a situação da pobreza absoluta a que a classe trabalhadora é submetida (CFESS, 2010, p. 21).

Contudo, ao mesmo tempo em que a luta pela afirmação dos direitos neste cenário torna-se um desafio é também fundamental, como parte do processo de acumulação de forças na direção de uma forma de desenvolvimento social inclusiva para todos os indivíduos sociais, conforme aponta o Código de Ética Profissional (IAMAMOTO, 2009).

Neste sentido, os assistentes sociais possuem um papel importante na consolidação e ampliação dos direitos sociais, desde a identificação das determinações sociais até a formulação e construção coletiva de estratégias políticas e técnicas para o desvelamento da realidade e o fortalecimento dos espaços de luta e organização dos

\footnotetext{
${ }^{23}$ Valor produzido pelo trabalhador a mais do que o seu salário e apropriado pelo capitalista. Serv. Soc. \& Saúde, Campinas, SP v. 13, n. 1 (17) p. 61-76 jan./jun. 2014 ISSN 1676-6806
} 
trabalhadores em defesa dos direitos sociais e pela ampliação destes, pois o assistente social busca nos aspectos sociais, econômicos, políticos e culturais as determinações sociais que interferem no processo saúde-doença (CFESS, 2010).

Ao tomar como base a concepção ampliada de saúde e o princípio da integralidade, o assistente social atua sobre diversas dimensões da vida dos usuários que, de alguma forma, interferem no processo saúde-doença, como: habitação, trabalho e renda, transporte e outros.

Assim, o ângulo particular de que dispõe o profissional assistente social torna-se essencial no processo de tratamento oncológico, uma vez que é o profissional que lida diretamente com as mazelas causadas pelas expressões da questão social, identificando as demandas e buscando articular as políticas sociais em prol de garantir as condições objetivas para que o tratamento seja efetivado. À medida que o assistente social atua na consolidação e na ampliação dos direitos sociais pode contribuir para melhorar as condições de vida e de trabalho dos usuários, ainda que não possam alterar estruturalmente o capitalismo.

Desta forma, por meio da atuação é possível contribuir para a reafirmação da direção social do Projeto Ético-Político nas respostas profissionais que encaminhamos, pautando-as no compromisso de viabilizar o exercício e ampliação dos direitos e, em última instância, com fins emancipatórios.

Iamamoto acrescenta:

Isso também implica decisão de ultrapassar a pequena política do diaa-dia, tal como se expressa na competência permitida e autorizada pelas organizações, restrita à prática manipulatória imediata e à recepção passiva das informações, que se traduz no empirismo nas rotinas, no burocratismo, que frequentemente se repõem no trabalho profissional (IAMAMOTO, 2009, p. 29).

Orientar o trabalho nos rumos aludidos requisita um perfil profissional culto, crítico e capaz de formular, recriar e avaliar propostas que apontem para a progressiva democratização das relações sociais. Exige-se, para tanto, compromisso ético-político com valores democráticos e competência teórico-metodológica baseada na teoria crítica em sua lógica de explicação da vida social (IAMAMOTO, 2009).

Nesta direção, cabe a reafirmação da saúde como resultante de políticas sociais e econômicas, ou seja, a saúde e o adoecimento inscritos na totalidade das relações sociais; e essa afirmação não nega o caráter particular do processo saúde-doença. 


\section{CONSIDERAÇÕES FINAIS}

No contexto de neoliberalismo, que vem sendo adotado no Brasil desde a década de 1990, o desmonte das políticas de proteção social são ratificadas e aprofundadas e, portanto, vivencia-se uma conjuntura extremamente desfavorável ao conjunto dos direitos conquistados historicamente. Neste sentido, tanto os que se referem ao mundo do trabalho, como os que se destinam à camada social fora do mercado de trabalho, que da mesma forma participam do ciclo de produção e reprodução do capital (ANTUNES, 2002; BEHRING, 2003).

Neste cenário, o trabalho em questão buscou destacar as potenciais consequências desta política de retração das políticas de proteção social no contexto de adoecimento, no caso, por carcinoma epidermóide, visto que a ausência de proteção social estatal ou a oferta limitada desta pode ser um fator determinante no processo saúde-doença.

A partir desta perspectiva, a saúde é entendida como resultado de políticas econômicas e sociais e o usuário enquanto ser social e histórico inserido em um determinado contexto que influencia sua condição de saúde e de efetivação do tratamento, o que significa inferir que as condições de vida e de trabalho dos usuários possuem papel determinante no processo saúde-doença, no sentido da garantia de todas as necessidades exigidas pelo adoecimento por essa patologia.

O assistente social inserido no contexto da saúde, dispõe de um ângulo particular de interpretação das condições de saúde e, portanto, no encaminhamento das demandas apresentadas. Desta forma, possui função importante na consolidação, ampliação e divulgação dos direitos sociais, como também na construção de estratégias para desvelar a precarização das condições de vida dos usuários.

Ao propor esta discussão o trabalho procurou apontar a relação entre políticas econômicas e sociais e adoecimento por câncer, no caso em questão, das políticas de proteção social e o adoecimento por carcinoma epidermóide, com vistas a destacar

elementos que contribuam para a reflexão crítica no debate sobre a garantia e ampliação dos direitos sociais.

Cabe ressaltar, por fim, a importância de investimento não só nas políticas que garantam o tratamento depois da doença estabelecida, mas também nas políticas de promoção e prevenção do câncer de pele, o que poderia incidir sobre a qualidade de 
vida dos usuários, nas taxas de incidência desta patologia e nos custos com a alta complexidade.

\section{REFÊRENCIAS BIBLIOGRÁFICAS}

ANTUNES, R. Os Sentidos do Trabalho: Ensaio sobre a afirmação e a negação do trabalho. São Paulo: Boitempo, 2002.

BATISTA SILVA. L. Condições de Vida e Adoecimento por Câncer. Juiz de Fora: Libertas, v.10, n.2, p.172-187, jul-dez 2010.

BEHRING, E. R. A Contra-Reforma do Estado no Brasil. São Paulo: Ed. Cortez, 2003.

BOSCHETTI, I. A Política de Seguridade Social no Brasil. In: CFESS/ABEPSS. Serviço Social: Direitos Sociais e Competências Profissionais. Brasília: CFESS/ABEPSS, p. 323-338, 2009.

BRASIL. Lei n. 8.080/90 de 19 de setembro de 1990. Dispõe sobre as condições para a promoção, proteção e recuperação da saúde.

BRASIL. Ministério da Saúde. Instituto Nacional de Câncer. Estimativas da Incidência de Câncer no Brasil: Estimativas 2012. Rio de Janeiro: INCA, 2011a.

BRASIL. Ministério da Saúde. Instituto Nacional de Câncer. Direitos sociais da pessoa com câncer. Divisão de Comunicação Social. 2. ed. 5a reimp. Rio de Janeiro: INCA, $2011 b$.

BRASIL. Ministério da Saúde. Instituto Nacional de Câncer. Situação do câncer no Brasil. Rio de Janeiro: INCA, 2005.

CFESS. Parâmetros para Atuação de Assistentes sociais na Política de Saúde. V. 2. Brasília, 2010.

FAVALLI. P. et al. Carcinoma epidermóide de pele: aspectos clínicos-patológicos e sociais. Porto Alegre: AMRIGS, v. 51, n. 4, p. 301-305, 2007.

HARVEY, D. Condição Pós-moderna: Uma Pesquisa sobre as Origens da Mudança Cultural. São Paulo: Ed. Loyola, 1993.

IAMAMOTO, M.V. Serviço Social em tempo de capital fetiche: capital financeiro, trabalho e questão social. São Paulo: Cortez, 2007. 
IAMAMOTO, M.V. O Serviço Social na Cena Contemporânea. In: CFESS/ABEPSS. Serviço Social: Direitos Sociais e Competências Profissionais. Brasília: CFESS/ABEPSS, 2009.

Disponível:

http://cressmt.org.br/upload/arquivo/pos_graducao_cfess_2010.pdf Acesso em: 03. nov 2012.

MOREIRA, M. C. O Serviço Social do INSS a partir da década de 1990: análise da implantação da matriz teórico-metodológica. In: BEHRING, E.B; ALMEIDA, M. H. T de (Orgs.) Trabalho e Seguridade Social: percursos e dilemas. São Paulo: Cortez, p. 235-252, 2010.

MOTA. A. E. Seguridade Social. Serviço Social \& Sociedade - Trocando em Miúdos, $\mathrm{n}^{\mathrm{o}}$ 50, Rio de Janeiro: Cortez, abril, p. 191 - 195, 1996.

MOTA. A. E. Serviço Social e Seguridade Social: uma agenda recorrente e desafiante. In: Em Pauta, Rio de Janeiro: UERJ, n. 20, p.126-139, 2007.

SALVADOR, E., AMORIM, A. Abordagens das Desigualdades Socioeconômicas no Brasil do Século XXI. Em Pauta, Rio de Janeiro: UERJ, v. 26, p. 31-47, 2010. 